\title{
THE RELATIONSHIP BETWEEN LAND USE, LAND COVER CHANGE, AND THE HEAT ISLAND EFFECT IN XI'AN CITY, CHINA
}

\author{
WANG, Z. F. ${ }^{1,2^{*}}-$ GONG, C. C. ${ }^{1,2^{*}}-$ BIAN, Z. H. ${ }^{1}$ \\ ${ }^{1}$ Key Laboratory of Subsurface Hydrology and Ecological Effect in Arid Region of Ministry of \\ Education, School of environmental science and engineering, Chang'an University \\ $X i$ 'an, Shaanxi, China \\ ${ }^{2}$ Engineering Research Center of Groundwater and Eco-Environment of Shaanxi Province, \\ Chang'an University, Xi'an, Shaanxi, China \\ (e-mail:wangzf@chd.edu.cn,895470127@qq.com,2437035537@qq.com) \\ ${ }^{*}$ Corresponding author \\ e-mail:wangzf@chd.edu.cn,895470127@qq.com
}

(Received 23 ${ }^{\text {rd }}$ Feb 2019; accepted $3^{\text {rd }}$ May 2019)

\begin{abstract}
With the acceleration of urbanization and the change of land use, the urban heat island effect has been significantly enhanced, leading to the rise of urban temperature, changing local air circulation, and influencing local microclimate. For investigating the temporal and spatial rules of the urban heat island effect in Xi'an City, China, this study combined Landsat TM, ETM remote sensing image, and surface meteorological station observation data to probe the trend of the urban heat island intensity in Xi'an City from 1993-2013 and to analyze its influencing factors. The results show that, from 1993 to 2009 , the heat island intensity presented an increasing trend, with a temperature rise rate of $0.38^{\circ} \mathrm{C} / 10 \mathrm{y}$, while the heat island intensity showed a decreasing trend from 2009 to 2013. There was a positive correlation between heat island intensity and the urban area in Xi'an city. By a comprehensive analysis, the expansion of the urban land area, the heat island intensity followed a constantly increasing radius of influence are the main reasons.
\end{abstract}

Keywords: urbanization, heat island intensity, urban land, forest land, farmland

\section{Introduction}

Urban heat island refers to a phenomenon of increasing urban surface and atmospheric temperature in comparison to peripheral non-urban environments as a result of urbanization (Peng et al., 2013; Soltanifard et al., 2019). Urban heat island intensity typically measured by the mean difference between urban temperature and suburban temperature. According to existing publications, due to the urban heat island effect, the urban temperature of a city is typically $2-5^{\circ} \mathrm{C}$ higher than its peripheral suburban temperature (Ackerman, 2010). In recent years, with the acceleration of urbanization, the original use patterns of natural land have changed considerably, and the construction of buildings, roads, and other impermeable surfaces (Estoque et al., 2017) have further fragmented the urban landscape, increased the urban area and population, and enhanced the urban heat island effect (Alberti et al., 2004; Ciren et al., 2012; Zhou et al., 2017). Before 1980, the urban-suburban difference in annual mean minimum temperature of Shijiazhuang City had been rising by $0.26^{\circ} \mathrm{C} / 10 \mathrm{y}$; after 1980 , it has been rising by about $1.7^{\circ} \mathrm{C} / 10 \mathrm{y}$ (Yang et al., 2013a). On the temporal and spatial change characteristics of the heat island effect of Nanjing City, since 1985, the heat island intensity and scope have both increased, and the area affected by the grade- 4 heat island effect in the built-up areas has increased by $107.88 \mathrm{~km}^{2}$ (Yang et al., 2007). Beijing City, the capital of the People's Republic of China, reported that the area 
affected by urban heat island effect has constantly increased (Wang et al., 2006). In the Athens region, during the research period, the difference between its urban temperature and its suburban temperature was very significant, with a rising rate of $0.2^{\circ} \mathrm{C} / 10 \mathrm{y}$ (Founda et al., 2015). The enhanced urban heat island effect has severely influenced both biodiversity and human life (Wu et al., 2014). Thus, in the context of changing patterns of urban land use, exploring the change rules and trend of the urban heat island effect has become one of the hotspot issues related to urban development under global climate change (Dong et al., 2011; Zhang, 2013a; Zhang et al., 2013b).

Studies on the urban heat island effect mainly conducted according to three methods: the ground meteorological data observation method, the remote sensing monitoring method, and the numerical simulation of the boundary layer (Yang, 2013b). Early studies mainly completed through an atmospheric temperature comparison between the urban and suburban areas of a city in the same period or of its different development stages (Song et al., 2009). With the development of remote sensing science and technology, the remote sensing monitoring method has become the primary method for investigating the heat island effect. In particular, aerospace sensors used to observe urban underlying surface temperature and other factors, while thermal infrared remote sensors are used to measure urban land cover temperature, thus obtaining heat distribution maps of different land covers via calculation and analysis (Yang, 2013b). For instance, remote sensing image for the inversion of land surface temperature and reported that changes in land use and land cover constitute the major drive behind the change in land surface temperatureb (Jiang et al., 2010). Other scholars (Chen et al., 2006; Qian et al., 2006; Xiao et al., 2007; Buyadi et al., 2013) reported that the increase of urban land area has led to a rise of land surface temperature, enhancing the urban heat island effect. The land surface temperature obtained through inversion via thermal infrared remote sensing can cover the land surface by a large scale, thus ensuring the relatively high spatial continuity and spatial resolution of the results (Voogt et al., 2003; Arnfield, 2003; Chen et al., 2012). However, given that the thermal infrared remote sensing phenomenon of the land surface is more significant during the daytime than during the nighttime, the results obtained with this method differ from the results calculated by atmospheric temperature data (Chen et al., 2012). It is thus clear that the data integration of aerial remote sensing and ground monitoring provides an effective method of researching the urban heat island effect.

With the acceleration of urbanization in China and the consequent increase of urban heat island intensity and expansion of heat island effect scope, accurately assessing and monitoring the development of the urban heat island effect has become particularly important at this point (Weilin et al., 2017). For explore the relationship between the urban heat island effect in Xi' an City and land use, land cover change (LUCC), this study integrated the remote sensing imaging technique and ground-measured atmospheric temperature data, probed into their relationships from both temporal and spatial scales, and analyzed the main controlling factors of the urban heat island effect through statistical comparison.

\section{Research Contents and Methods}

\section{Research area}

The study area, the Xi'an city, the People's Republic of China, located in the middle of the Guanzhong Basin, consisting of nine districts and four counties (geographical 
coordinates: $33^{\circ} 49^{\prime} \mathrm{N}-34^{\circ} 45^{\prime} \mathrm{N}, 107^{\circ} 40^{\prime} \mathrm{E}-109^{\circ} 49^{\prime} \mathrm{E}$ ). Xi' an city, situated between the Weihe River on the north and the Qinling Mountains on the south and adjoining, with the Taibai Mountain on the west and the Weinan City on the east. It is a temperate continental climate, with an annual mean temperature of $13.00^{\circ} \mathrm{C}$ and annual mean precipitation of $604.2 \mathrm{~mm}$. It's maximum north-south width, and east-west lengths are about $116 \mathrm{~km}$ and $204 \mathrm{~km}$, respectively. The total area of the city is $10,108 \mathrm{~km}^{2}$.

\section{Data sources}

The temperature observation data came from the surface meteorological stations distributed in the urban districts and in Chang'an District, Lantian County, Gaoling County, Lintong County, Huxian County, and Zhouzhi County (Fig. 1). In particular, the annual mean temperature data of 1993, 1995, 2000, 2006, 2009, and 2013 were used to investigate the changing trend of heat island intensity; monthly mean temperature data were used to explore the spatial rules of heat island intensity change.

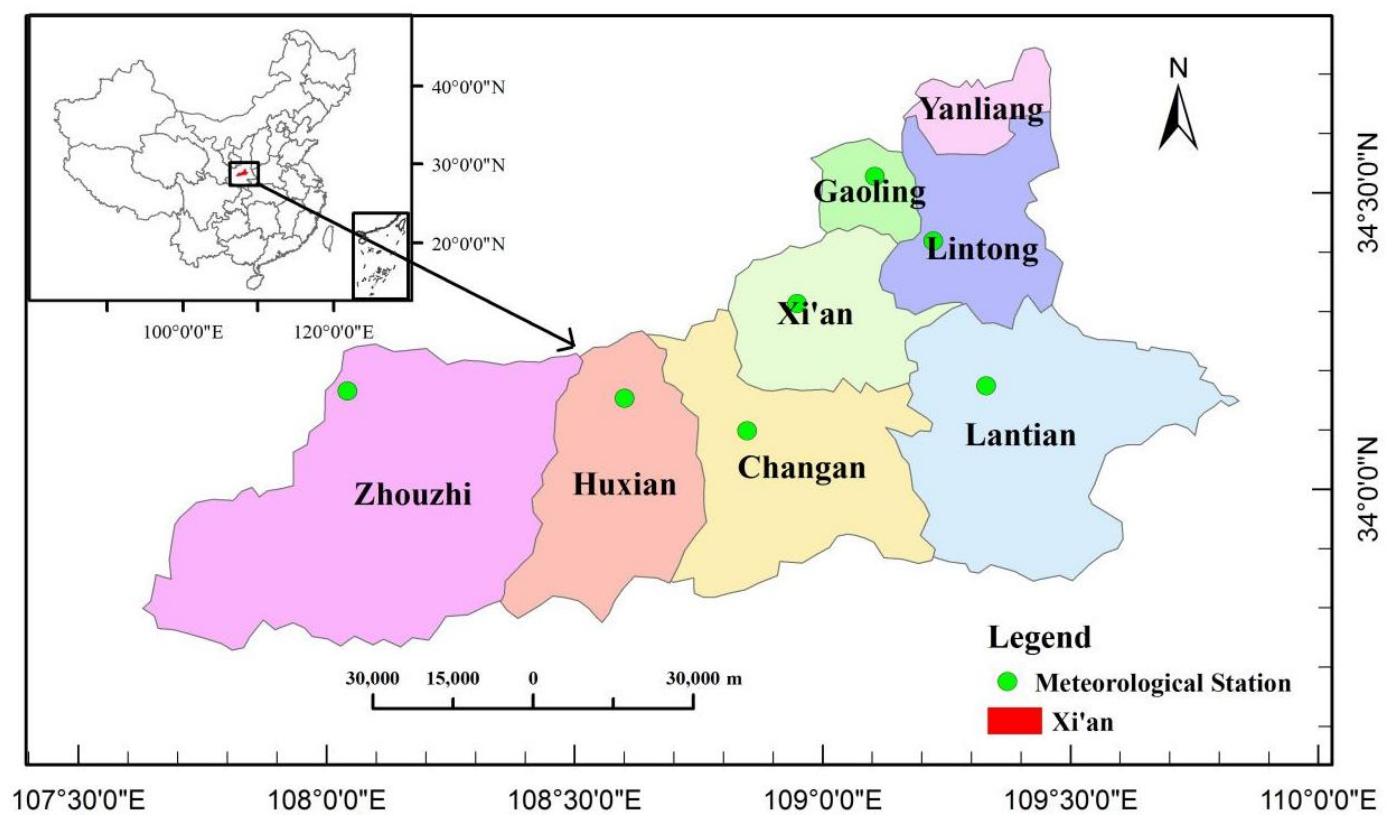

Figure 1. Xi'an Administrative Region

The remote sensing images were derived from the Geospatial Data Cloud of the Chinese Academy of Sciences (CAS), and Landsat TM and ETM remote sensing image data were selected from six years, i.e., 1993-6-18, 1995-6-8, 2000-5-20, 2006-7-24, 2009-6-30, and 2013-6-29.

\section{Data processing}

(1) The ENVI5.1 software used for the interpretation of remote sensing images and the supervised classification method was used to classify these images. According to national standards (Classification of land use status, GB/T 21010-2017), there are a total of six land use types, i.e., urban land, forest land, grassland, farmland, water area, and unused land. Based on the areas of various land use types obtained through statistical methods, a comparison conducted between acquired data and data from the statistical 
yearbooks, with the purpose of ensuring that the acquired data all fall within the allowable error range.

(2) Calculation of urban heat island intensity was done with the following formula:

$$
\Delta T_{u-r}=T_{u}-\frac{1}{n} \sum_{i=1}^{n} T_{r}
$$

where, $\Delta T_{u-r}$ is the urban heat island intensity; $T_{u}$ is the annual mean temperature of downtown districts; $T_{r}$ represents the annual mean temperature of suburban areas, covering six districts (counties), i.e., Chang'an District, Lantian County, Gaoling County, Lintong County, Huxian County, and Zhouzhi County; and n represents the number of suburban meteorological stations $(n=6)$.

\section{Statistical analysis}

The correlation between heat island intensity and various land cover types was analyzed according to the multivariate stepwise regression analysis and using SPSS software.

\section{Results}

\section{Spatial change of the heat island effect in Xi'an City}

Fig. 2 shows the temporal and spatial change rules of the temperature of Xi'an City. As can be seen from the interpretation of the remote sensing images during 1993-2009, the area of urban land showed a significantly increasing trend, and the area of downtown Xi'an City significantly increased as well. In the mountainous terrain of the Qinling Mountains to the south, and affected by human activities, the farmland and urban land of the intermontane valley region all increased, further fragmenting the forest there. The water area in this region accounted for a small proportion and did not present any significant change trend. Correspondingly, as indicated by the isothermal diagram of Xi' an City, with the expansion of urban land area, the isothermal diagram became more concentrated, pointing toward an increase of temperature gradients.

For comparatively analyze the changes in the urban heat island effect, this study calculated the change values of urban heat island intensity with time (Eq. 1). Affected by urban expansion and human activities, the mean temperature of Xi' an City increased significantly (Fig. 3). From 1993-2009, its urban heat island intensity presented a significantly increasing trend and increased from 0.42 in 1993 to 1.0 in 2009, and the five-year mean temperature rising rate of the city was $0.19^{\circ} \mathrm{C} / 5 \mathrm{y}$. Thus it is clear that after 2009, the urban heat island intensity index presented a decreasing trend. To discuss the cause of such a decrease, we evaluated the data of the statistical yearbooks of Xi'an City. According to statistical data from 2009 to 2013, the population of the city increased from 8.4346 million to 8.5881 million, and its urban land area was also constantly increased. However, it's forest land area remained unchanged. The improved urban landscape construction and increased green area weakened its heat island intensity to some extent (Huang et al., 2012). Furthermore, the climatic environment and local weather conditions also influenced the urban heat island effect, including inversion intensity, cloud cover, wind speed, wind direction, relative humidity, precipitation, and sunshine duration(Wang et al., 2006; Liu et al., 2008; Huang, 2011). 


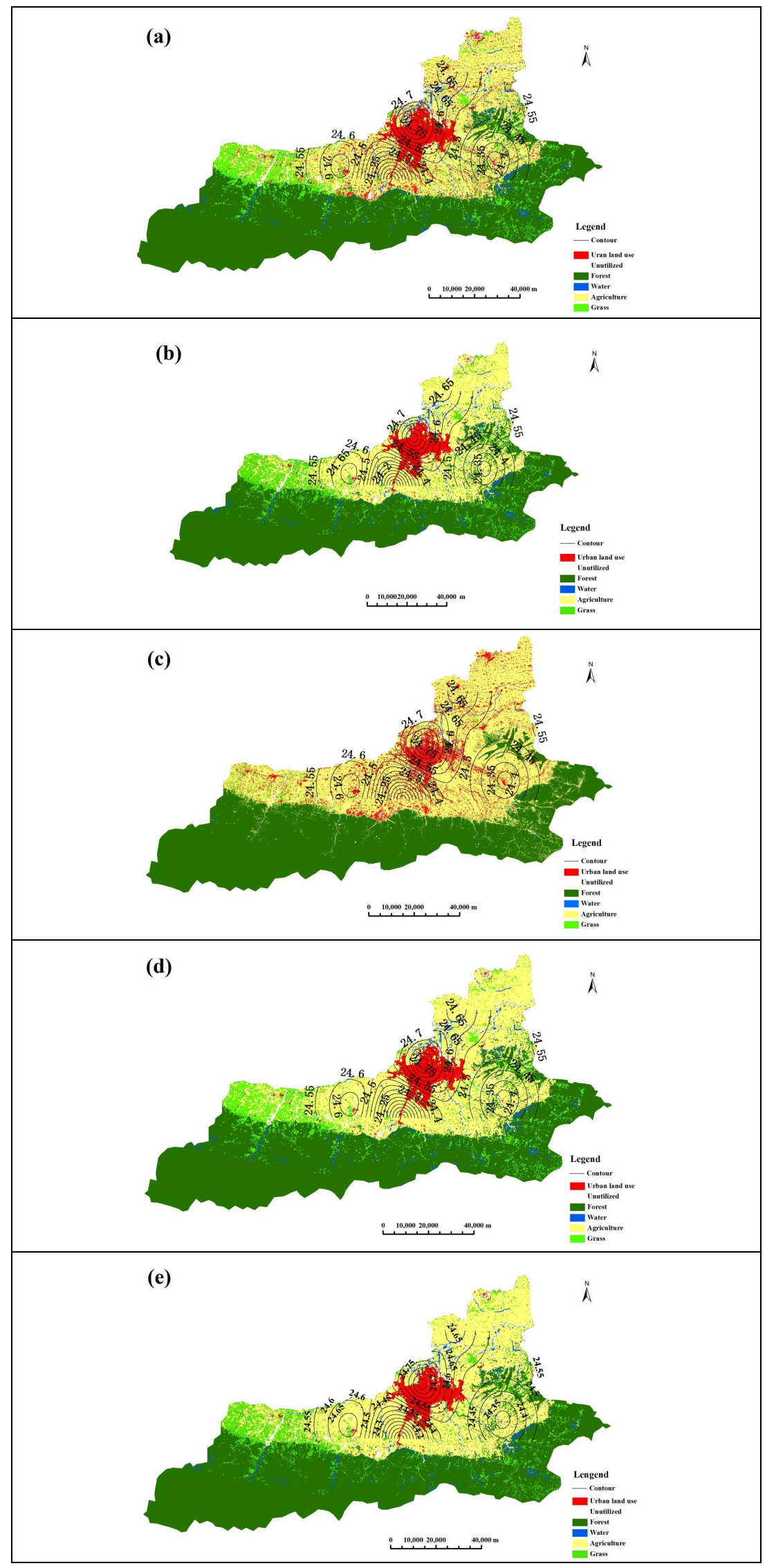

Figure 2. Temporal and spatial changes in the temperature of Xi'an City 


\section{The relationship between heat island intensity and land use change of Xi'an City}

To further analyze the relationship between heat island effect and land use in Xi'an City, remote sensing images were used to extract the urban land area, farmland area, forest land area and water area in the period of 1993-2009 to comparatively analyze their changing trends with time. Fig. 4 depicts the change trends of the proportions of the urban land area, farmland area, forest land area, and water area in the total land area of Xi'an City with time. In summary, the urban land area of Xi'an City presented an increasing trend from 0.086 in 1993 to 0.100 in 2013. Xi'an's farmland area decreased from 0.316 in 1993 to 0.242 in 2013, while it's forest land area presented an increasing trend from 0.344 in 1993 to 0.503 in 2006 . However, from 2006-2009, the water area showed a decreasing trend before 2000, an increasing trend observed after 2006.

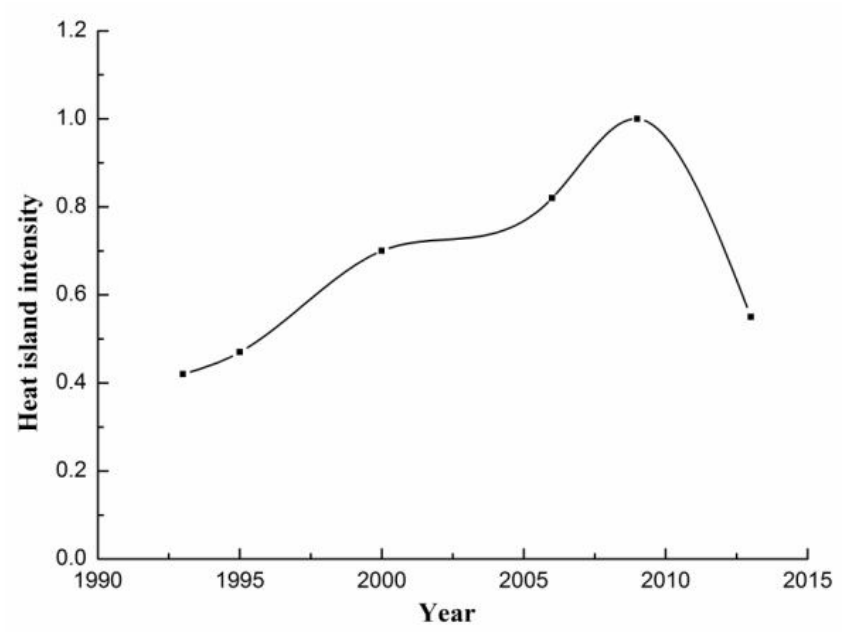

Figure 3. Change trend of the urban heat island intensity of Xi'an City

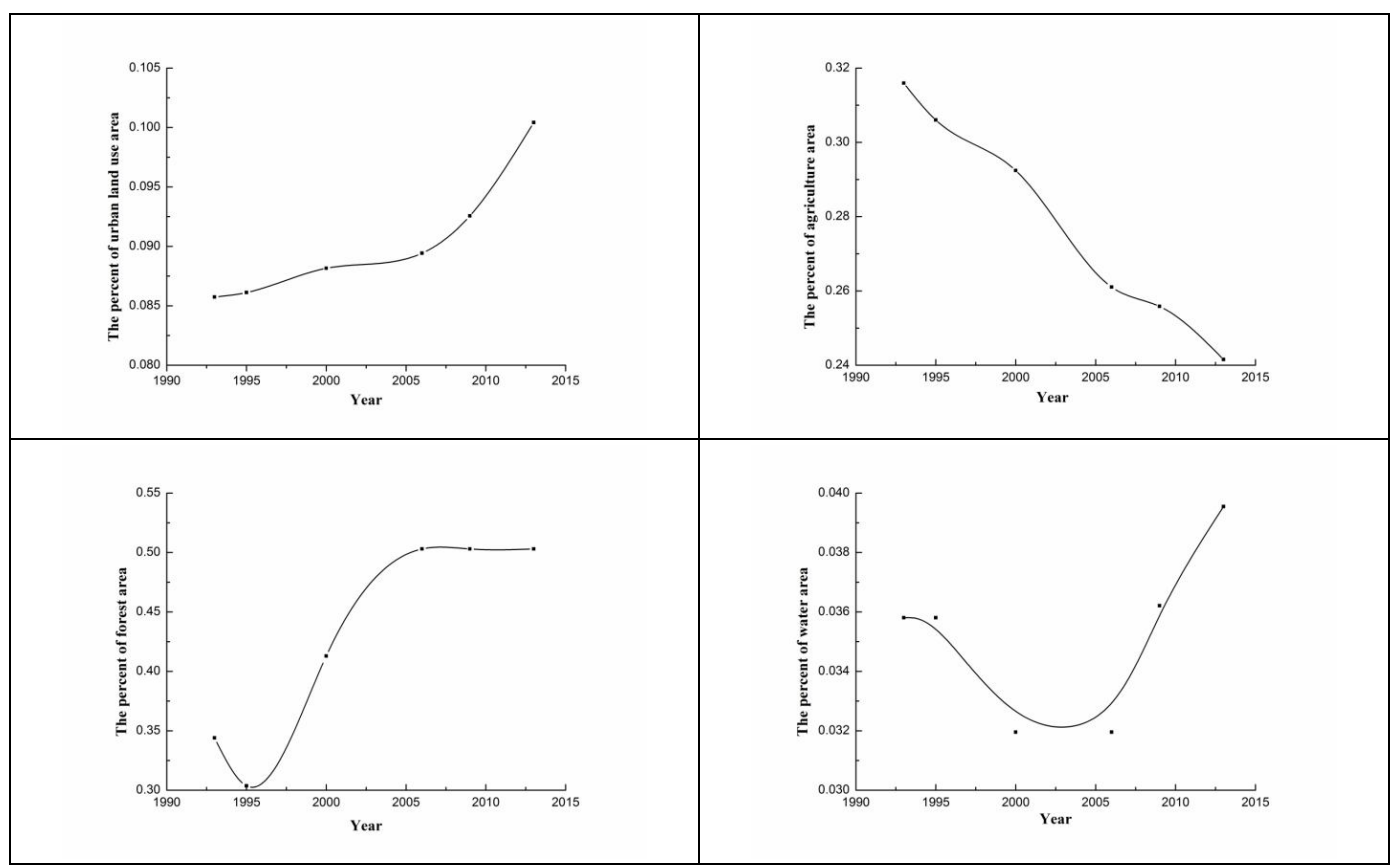

Figure 4. Trend chart of main land use patterns of Xi'an City 


\section{Correlation between land use area change and heat island intensity of Xi'an City}

Multivariate stepwise regression analysis was employed to analyze the correlation between the change of land use and heat island intensity, as well as to quantitatively investigate the correlation between heat island intensity and the areas of various land use types. The analysis results presented in Table 1.

Table 1. Relationship between land use change and heat island intensity of Xi'an City

\begin{tabular}{c|c|c|c|c}
\hline Land use types & Urban land & Farmland & Forest land & Water area \\
\hline $\begin{array}{c}\text { Coefficient of } \\
\text { correlation }\end{array}$ & 0.985 & -0.965 & 0.938 & -0.223 \\
\hline
\end{tabular}

The analysis results show a positive correlation between heat island intensity and urban land area (coefficient of correlation $=0.985$ ), suggesting that the increase of urban land area exerted a very significant influence on the heat island intensity. A positive correlation was observed between heat island intensity and farmland area, as the decrease of farmland area would enhance the heat island effect. A positive correlation also observed between heat island intensity and forest land area, which is inconsistent with the results reported in other studies (Zhang et al., 1988; Liu, 2007; Liu et al., 2011). It's might because Xi'an City leans on the Qinling Mountains on the south and its forest land mainly distributed in the mountainous terrain of the Qinling Mountains. However, the airflow motion of Xi'an City mainly influenced by the northwest monsoon climate. In other words, the forest land of the mountainous terrain of the Qinling Mountains exerted no significant influence on the heat island effect of Xi'an City (Miao, 1998; Wang et al., 2008; Miao, 2014). A negative correlation found between heat island intensity and water area. However, the correlation was not strong, mainly because the water area in this region only accounted for a small proportion. After 2006, the water area showed an increasing trend, but small-area urban water bodies still exerted no significant regulatory effect on urban temperature (Liu et al., 2011).

To this regard, this study introduced multivariate stepwise regression analysis to investigate the relationship between the proportions of the urban land area, farmland area, forest land area, and water area in the total land area of Xi'an City and its heat island intensity. The results of stepwise regression shown in Table 2, and the regression model acquired:

$$
Y=85.912 X_{1}-6.913
$$

where $\mathrm{Y}$ represents heat island intensity, and $\mathrm{X}_{1}$ represents the proportion of urban land area in the total land area.

Table 2. Stepwise regression analysis results

\begin{tabular}{c|cc|c|c|c}
\hline \multirow{2}{*}{ Model } & \multicolumn{2}{|c|}{ Unstandardized coefficient } & Standardized & \multirow{2}{*}{ t } & \multirow{2}{*}{ Sig. } \\
\cline { 2 - 4 } & B & $\begin{array}{c}\text { Standardized } \\
\text { coefficient }\end{array}$ & Trial version & & 0.003 \\
Constant & -6.913 & 0.769 & 0.985 & -8.992 & 0.883 \\
Urban land & 85.912 & 8.693 & & 0.002 \\
\hline
\end{tabular}

All correlations were statistically significant $(\mathrm{p}<0.01)$ 


\section{Discussion}

During recent years and with the acceleration of urbanization, China's large and medium-sized cities have witnessed an enhanced urban heat island effect (Weilin et al., 2017). Zigong City, in Sichuan Province, P. R. China, experienced relatively fast urbanization from 2000 to 2009, and the significant increase of urban land area changed the nature of the urban surface, thus enhancing the heat island effect (Deng et al., 2015). Guo et al. (2015) explored the thermal environmental characteristics and heat island intensity of urban villages in Shenzhen City and discovered a significant heat island effect in these villages. Using remote sensing images, Yao et al. (2013) analyzed the temporal and spatial change characteristics and causes for the heat island effect in Hefei, and the results show that the spatial distribution and extension of heat islands matched the layout of the city's built-up areas in the period of 1995-2010. Furthermore, the scope of heat islands continuously expanded with the development of Hefei city. In Shenyang City, P. R. China, compared to 2001, the year 2010 saw a significantly expanded urban heat island area (Wang et al., 2015). Heat island intensity, being closely related to LUCC, population, greening, and urban landscape environment, which is also influenced by the sum of climatic environmental and local weather conditions. In particular, local weather and meteorological conditions constitute the external cause, while land use change incurred by population growth, urbanization, and industrialization constitute the internal cause (Peng et al., 2013). Focused on the influence of the urbanization development of City on the heat island effect, Wang et al. (2010) found that the urban heat island effect of Shanghai City has gradually enhanced during recent years, mainly due to the increase of population density and the increase of built-up areas to a very large extent. Feng (2011) investigated the heat island effect in the metropolitan circle of Xi' an City and found the heat island effect in all the typical towns in its metropolitan circle to varying extents. In Liaoning Province, among the six cities, five suffered from an enhanced heat island effect ( $\mathrm{Li}$ et al., 2012). Also, many other domestic cities experienced a heat island effect to varying degrees, and with the warming of the global climate and the acceleration of urbanization, the heat island effect gradually enhanced in China (Ran, 2010; Li, 2012). From the above results, we can say that the heat island effect poses a significant threat to human life and health. Therefore, it is of vital importance to decrease heat island intensity. Judging from the research results of this study, the urban heat island effect of Xi'an City presents an enhancing trend, mainly as a result of the increased urban area.

According to existing research, a negative correlation exists between the urban heat island effect and forest land area (Yang et al., 2007, 2014; Dai et al., 2009; Liu et al., 2011; Chen et al., 2012). However, according to our research, there is a positive correlation between urban heat island intensity and forest land area of Xi'an City. We think mainly due to two reasons. Firstly, Xi' an City leans to the Qinling Mountains on the south and its forest land mainly distributed in the mountainous terrain of the Qinling Mountain. However, the forest land area accounted for an extremely small proportion of the total land area of $\mathrm{Xi}^{\prime}$ an City and did not change significantly. Therefore, the forest land in the mountainous terrain of the Qinling Mountains exerts no significant influence on its heat island intensity. Secondly, the prevailing wind in the Xi'an region is an easterly-westerly wind, and the Qinling Mountains on the south only block the entry of southerly airflow but exert no significant influence on the climate or general circulation of Xi' an City. The relatively weak correlation between heat island intensity and water area is due to the area of urban water bodies in Xi'an being relatively small and 
absorbing only a small proportion of surface heat. Consequently, water area exerts no significant influence on urban temperature.

Urbanization represents an inevitable trend of development all over the world, signifying the progress of human civilization (Li, 2006). The increasingly rapid urbanization has increased land surface temperature will no doubt intensely influence the mass and energy flows of the urban ecosystem, change its structure and functions, produce a series of eco-environmental effects, and impact urban climate, urban hydrology, urban soil physicochemical properties, urban atmospheric environment, urban biological habits, urban material cycle, urban energy metabolism, and urban residential health (Bo et al., 2005). The heat island effect is one of the extremely severe problems caused by urbanization. An extreme weather environment, particularly an extreme thermal environment, exerts a considerable influence on both mortality and morbidity. As an extra factor in the thermal environment, the heat island effect not only threatens human health but also increases mortality; furthermore, intensifies air pollution and increases energy consumption (Ketterer et al., 2014). Thus, to weaken the heat island effect, in the development process of its urbanization, Xi'an City should strengthen urban landscape construction, increase the extent of green and water area, control the increase of urban land area, and seek more rational patterns, scale, and spatial distribution of land use.

\section{Conclusions}

This study integrated the remote sensing imaging technique with ground-measured atmospheric temperature data, probed into the relationship between the urban heat island effect and LUCC from both temporal and spatial scales, and analyzed the main controlling factors of the urban heat island effect via statistical comparison. The mainly results as follows:

(1) From 1993 to 2009, the heat island intensity of Xi'an City presented an increasing trend, with a rate of temperature rise of $0.193^{\circ} \mathrm{C} / 5 \mathrm{y}$. However, from 2009 to 2013 , its heat island intensity showed a decreasing trend, which might be related to both landscape construction and greening and the entire climatic environment.

(2) The heat island intensity of Xi'an City mainly influenced by urban land area, farmland area, increasing urban land area and decreasing farmland area. The city's heat island intensity increased. The stepwise regression analysis model for the correlation between heat island intensity and the urban land area in Xi' an City is $\mathrm{Y}=85.912 \mathrm{X}_{1}$ 6.913.

Acknowledgements. This work was supported by the National Science Foundation of China (NSFC, Grant No. 41202164), and the Open Research Fund of State Key Laboratory of Loess and Quaternary Geology, Institute of Earth Environment, CAS (Grant No. SKLLQG1623).

\section{REFERENCES}

[1] Ackerman, B. (2010): Temporal march of the Chicago heat island. - Journal of Applied Meteorology 24(6): 547-554.

[2] Alberti, M., Marzluff, J. M. (2004): Ecological resilience in urban ecosystems: linking urban patterns to human and ecological functions. - Urban Ecosystems 7(3): 241-265. 
[3] Arnfield, A. J. (2003): Two decades of urban climate research: a review of turbulence, exchanges of energy and water, and the urban heat island. - International Journal of Climatology 23(1): 1-26.

[4] Buyadi, S. N. A., Wan, M. N. W. M., Misni, A. (2013): Impact of land use changes on the surface temperature distribution of the area surrounding the national botanic garden, Shahalam. - Procedia Social and Behavioral Sciences 101: 516-525.

[5] Chen, X. L., Zhao, H. M., Li, P. X., Yin, Z. Y. (2006): Remote sensing image-based analysis of the relationship between urban heat island and land use/cover changes. Remote Sensing of Environment 104(2): 133-146.

[6] Chen, A. L., Sun, R. H., Chen, L. X. (2012): Studies on urban heat island from a landscape pattern view: a review. - Acta Ecologica Sinica 14: 4553-4565. (in Chinese with English abstract).

[7] Ciren, L., Zhuo, G., Luo, B., Ciren, P. (2012): Temporal and spatial distribution of urban heat islands around Lhasa city. - Resources Science 34(12): 2364-2373.

[8] Dai, X. Y., Zhang, L. Q., Guo, Z. Y., Wu, J. P., Li, X. D., Zhu, Y. L. (2009): Mechanism of formation of urban heat island effect and its spatial pattern in Shanghai. - Acta Ecologica Sinica 07: 3995-4004.

[9] Deng, C., Yang, W. (2015): Spatial and temporal study on urban heat island in Zigong city, China based on TM data. - Earth and Environment 01: 86-91.

[10] Dong, H. Y., Hou, J. W., Liu, X. Z. (2011): Study on urban heat island effect in the Qingdao area. - The annual meeting of the twenty-eighth China Meteorological SocietyS7 city weather forecast and service. Shamen (in Chinese).

[11] Estoque, R. C., Murayama, Y. Myint, S. W. (2017): Effects of landscape composition and pattern on land surface temperature: an urban heat island study in the megacities of southeast asia. - Science of the Total Environment DOI: 10.1016/j.scitotenv.2016.10.195.

[12] Feng, X. G. (2011): Study on the evolution of urban heat island effect and the cause of formation of Urban Heat Island [D]. - Shanxi Normal University (in Chinese).

[13] Founda, D., Pierros, F., Petrakis, M., Zerefos, C. (2015): Interdecadal variations and trends of the urban heat island in Athens (Greece) and its response to heat waves. Atmospheric Research 161-162: 1-13.

[14] Guo, Q., Zou, Z., Hongyong, L. I., Qiu, G. (2015): Analysis of the thermal environment of an urban village in Shenzhen. - Ecology \& Environmental Sciences 03: 427-435.

[15] Huang, L. P. (2011): Study on urban heat island effect in the Tianjin area. - Nanjing University of Information Science \& Techonlogy (in Chinese).

[16] Huang, J. C., Zhao, X. F., Tang, L. N., (2012): Analysis of spatiotemporal changes of urban thermal landscape pattern in the context of urbanization: a case study of Xiamen City. - Acta Ecologica Sinica 02: 622-631. (in Chinese with English abstract).

[17] Jiang, J., Tian, G. (2010): Analysis of the impact of land use/land cover change on land surface temperature with remote sensing. - Procedia Environmental Sciences 2(1): 571575.

[18] Ketterer, C., Matzarakis, A. (2014): Human-biometeorological assessment of the urban heat island in a city with complex topography - the case of Stuttgart, Germany. - Urban Climate 10(10): 573-584.

[19] Li, B. C. (2006): Problems of municipal ecological environment and the sustainable development in China. - Journal of Arid Land Resources \& Environment 20(2): 1-6. (in Chinese with English abstract).

[20] Li, J. Q. (2012): Dynamic change analysis for heat island effects of Hefei based on remote sensing data and landscape ecology theory. - Anhui Agricultural University.

[21] Li, L. G., Wang, H. B., Jia, Q. Y., Lü, G. H., Wang, X. Y., Zhang, Y. S., Ai, J. F. (2012): Urban heat island intensity and its grading in Liaoning province of northeast China. Chinese Journal of Applied Ecology 23(5): 1345-1350. (in Chinese with English abstract). 
[22] Liu, Y. (2007): Advance in the study on urban landscape pattern and heat island effect. Journal of Meteorology \& Environment 06: 46-50. (in Chinese with English abstract).

[23] Liu, Z. N., Yin, X. J. (2008): Urban heat island effect and meteorologic factors in Xi'an. Journal of Arid Land Resources and Environment 22(2): 87-90. (in Chinese with English abstract).

[24] Liu, K., Xingfa, G. U., Tao, Y. U., Gao, Z., Gao, W. (2011): Relationships between urban heat island effect and land use and land cover change around urban weather stations. Climatic \& Environmental Research 16(6): 707-716. (in Chinese with English abstract).

[25] Miao, M. Q. (1998): The interaction between sea and land breeze and heat island circulation during the summer over the delta region of the Yangtze river and urbanization effect on climate. - Plateau Meteorology 03: 59-68. (in Chinese with English abstract).

[26] Miao, J. F. (2014): An overview of numerical studies of the interaction of urban heat island and sea breeze circulations. - Transactions of Atmospheric Sciences 04: 521-528. (in Chinese with English abstract).

[27] Peng, B., Shi, Y., Wang, H., Wang, Y. (2013): The impacting mechanism and laws of the function of urban heat islands effect: a case study of Shanghai. - Acta Geographica Sinica 68(11): 1461-1471. (in Chinese with English abstract).

[28] Qian, L. X., Cui, H. S., Chang, J. (2006): Impacts of land use and cover change on land surface temperature in the Zhujiang delta 1. - Pedosphere 16(6): 681-689. (in Chinese with English abstract).

[29] Ran, G. (2010): Analysis of urban heat island effect in Ji'nan. - Meteorological Science \& Technology S1: 97-101. (in Chinese with English abstract).

[30] Soltanifard, H., Aliabadi, K. (2019): Impact of urban spatial configuration on land surface temperature and urban heat islands: a case study of mashhad, iran. - Theoretical and Applied Climatology. https://doi.org/10.1007/s00704-018-2738-4.

[31] Song, X., Duan, J., Du, L. (2009): Research overview of the urban heat island effect. Meteorological \& Environmental Sciences 32(3): 68-72. (in Chinese with English abstract).

[32] Voogt, J. A., Oke, T. R. (2003): Thermal remote sensing of urban climates. - Remote Sensing of Environment 86(3): 370-384.

[33] Wang, W. J., Shen, W. M., Liu, X. M., Zhang, F., Pan, Y. Z., Luo, H. J. (2006): Research on the relation of the urbanization and urban heat island effect changes in Beijing based on remote sensing. - Research of Environmental Sciences 19(2): 44-48. (in Chinese with English abstract).

[34] Wang, X. Q., Wang, Z. F. (2006): The study of the urban heat island in Beijing city. Climatic \& Environmental Research 11(5): 627-636. (in Chinese with English abstract).

[35] Wang, X. Q., Wang, Z. F., Gong, Y. B. (2008): Modulation of urban heat island circulation on the mountain-plain wind in the Beijing area. - Climatic \& Environmental Research 13(5): 639-644.

[36] Wang, G. X., Shen, X. L. (2010): On the relationship between urbanization and heat island effect in Shanghai. - Journal of Subtropical Resources \& Environment 02: 1-11. (in Chinese with English abstract).

[37] Wang, H. B., Li, L. G., Zhao, Z. Q., Cai, F., Wu, J. W., Xu, S. L., Jiang, P. (2015): Urban heat island variation of each district in Shenyang based on TM/ETM+ data. - Chinese Journal of Ecology 34(1): 219-226. (in Chinese with English abstract).

[38] Weilin, L., Xiaoping, L., Dagang, W., Yanling, S. (2017): The impact of energy consumption on the surface urban heat island in china's 32 major cities. - Remote Sensing doi:10.3390/rs9030250.

[39] Wu, H., Ye, L. P., Shi, W. Z., Clarke, K. C. (2014): Assessing the effects of land use spatial structure on urban heat islands using hj-1b remote sensing imagery in Wuhan, China. - International Journal of Applied Earth Observation \& Geoinformation 32(1): 6778. (in Chinese with English abstract). 
[40] Xiao, R. B., Ouyang, Z. Y., Li, W. F., Zhang, Z. M., Jr Tarver, G., Wang, X. K., Miao, H. Z. (2005): A review of the eco-environmental consequences of urban heat islands. - Acta Ecologica Sinica 25(8): 2055-2060. (in Chinese with English abstract).

[41] Xiao, H., Weng, Q. (2007): The impact of land use and land cover changes on the land surface temperature in a karst area of China. - Journal of Environmental Management 85(1): 245-257. (in Chinese with English abstract).

[42] Yang, Y. B., Wei-Zhong, S. U., Jiang, N., Zhen, F. (2007): Temporal and spatial characteristics of urban heat island effect change of Nanjing city and its relation with land use change. - Geographical Research 26(5): 877-876. (in Chinese with English abstract).

[43] Yang, B. (2013): The progress of urban heat island effect. - Journal of Meteorology \& Environment 29(2): 101-106. (in Chinese with English abstract).

[44] Yang, P., Chen, J., Hou, X. W., Gao, Q., Zhao, Q. (2013): Study of Urban heat island based on multi-source data by the example of the Shijiazhuang Area. - Meteorological Monthly 10: 1304-1313. (in Chinese with English abstract).

[45] Yang, P., Chen, J., Gao, Q. (2014): Effect of different land cover types on urban heat island. - The annual meeting of the thirty-first China Meteorological Society S11-The third city meteorological Forum - city and environment. Beijing:14 (in Chinese).

[46] Yao, Y., Liu, P., Chen, L. (2013): Spatiotemporal variation characteristics and causes of urban heat islands in Hefei city, Anhui province of China based on remote sensing. Chinese Journal of Ecology 12: 3351-3359. (in Chinese with English abstract).

[47] Zhang, J., Liu, Q. (1988): Temporal variations 1 n the relationship between urban temperature and the structure of the urban surface in Beijing. - Acta Geographica Sinica 2: 159-168. (in Chinese with English abstract).

[48] Zhang, Z. (2013): Analysis on Heat Island Effect in Coastal Urbanization Area Using Remote Sensing Data: A Case Study in the Qingdao Area. - Ocean University of China (in Chinese).

[49] Zhang, H., Qi, Z. F., Ye, X. Y., Cai, Y. B., Ma, W. C., Chen, M. N. (2013): Analysis of land use/land cover change, population shift, and their effects on spatiotemporal patterns of urban heat islands in metropolitan Shanghai, China. - Applied Geography 44(4): 121133. (in Chinese with English abstract).

[50] Zhou, B., Rybski, D., Kropp, J. P. (2017): The role of city size and urban form in the surface urban heat island. - Scientific Reports DOI:10.1038/s41598-017-04242-2. 